\title{
Elementary Reactions in the Cationic Oligomerization of 2-Alkoxy- 1,3,2-Dioxaphospholane with Alkyl Iodide as Initiator
}

\author{
Yuhsuke KawaKami, ${ }^{*}$ Kazushi Miyata, and Yuya Yamashita \\ Department of Synthetic Chemistry, Nagoya \\ University, Nagoya 464, Japan.
}

(Received February 13, 1978)

\begin{abstract}
Elementary reactions in the oligomerization reaction of 2-alkoxy-1, 3, 2dioxaphospholanes by alkyl iodides were studied. The initial reactions were ring-opening reactions leading to open-chain phosphonate and isomerization reactions with loss of an external alkyl group leading to cyclic phosphonate. The ratio of these two elementary reactions was 2.7: 1.0 in the reaction of 2-methoxy-1, 3, 2-dioxaphospholane with methyl iodide at $70^{\circ} \mathrm{C}$. The reaction with ethyl iodide was much slower compared to that with methyl iodide. This suggests the slow propagation of the polymerization of 1,3,2-dioxaphospholanes by methyl iodide. The isomerization reaction could be a chain-transfer reaction in the growing chain. This might be the reason why high polymers could not be obtained from 2-methoxy-1, 3, 2-dioxaphospholane. The reaction of 2-t-butoxy-1, 3, 2-dioxaphospholane with methyl iodide was exclusively the isomerization process via the Arbuzov reaction, with removal of the external $t$-butyl group, which led to isobutylene. In the reaction of 2-neopentoxy-1, 3, 2-dioxaphospholane with methyl iodide, the only product resulted from the addition of methyl iodide to the dioxaphospholane ring, followed by ring opening.

KEY WORDS Cationic Oligomerization / Dioxaphospholane / Alkyl Iodide / Arbuzov Reaction / Elementary Reaction / Isomerization / Addition / Ring Opening /
\end{abstract}

The cationic polymerization of 1,3,2-dioxaphospholane derivatives has been studied by Petrov, ${ }^{1,2}$ Mukaiyama, ${ }^{3,4}$ Shimidzu, ${ }^{5,6}$ Harwood, ${ }^{7}$ Yamashita, ${ }^{8}$ and Vogt. ${ }^{9}$ The principal driving force for the ring-opening polymerization of 1,3 , 2-dioxaphospholanes would be the ring strain in the phospholane ring and the affinity between the phosphorus atom and the oxygen atom forming the $\mathbf{P}=\mathbf{O}$ bond. Thus, the $\mathbf{P}=\mathbf{O}$ was considered to be contained in the polymer structure, and the suggested structure of the polymer was the phosphonate or phosphinate through the Arbuzov reaction, with ring opening as shown in the following equation

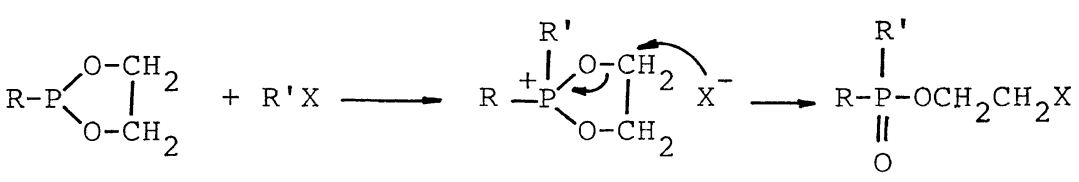

[I]

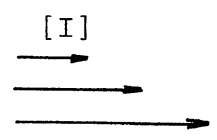

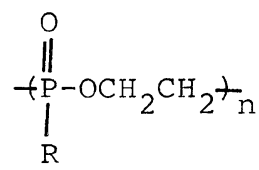


where $\mathrm{R}=\mathrm{Ph}$ or $\mathrm{MeO}$.

However, in the polymerization of 2-methoxy-1, 3, 2-dioxaphospholane, it has also been pointed out that there are some unusual features in the polymer structure. Shimidzu suggested that the isomerization of monomer to pentavalent phosphonate occurred, ${ }^{5,6}$ and Harwood proposed the reinitiation from the formed polymer ${ }^{7}$. Recently, Vogt studied the polymerization of 2-phenoxy-1, 3,2-dioxaphospholane by benzyl bromide and found that the principal structure of the polymer was 1, 2-ethanediphosphonate ${ }^{9}$. He suggested the cleavage of the oxygen-methylene bond of the $\mathrm{POCH}_{2}$ ester linkage in the penultimate unit of the growing phosphonium ion by the attack of bromide ion, giving phosphonate anion and $\beta$-brominated phosphonium ion, and the attack back on the ring methylene of the phosphonium ion by the phosphonate anion, forming the 1, 2-ethanediphosphonate unit. It is of interest to investigate the elementary reactions between 2-alkoxy-1, 3, 2dioxaphospholanes and alkyl iodides in order to elucidate the reaction mechanism in the oligomerization of the monomers.

\section{EXPERIMENTAL SECTION}

\section{Reagents}

Phosphorus trichloride, methyl iodide- $d_{3}$, methyl bromide, and aluminum chloride were used without further purification. Ethylene glycol and triethylamine were distilled over calcium hydride. Methanol was distilled over magnesium methoxide, Tertiary butyl and neopentyl alcohols were distilled under nitrogen. Dichloromethane, chloroform, and 1,1,2,2-tetrachloroethane were distilled over phosphorus pentoxide. Benzene, ligroin, and diethyl ether were distilled over lithium aluminum hydride.

\section{Synthesis of Monomers}

2-Chloro-1, 3, 2-dioxaphospholane was obtained by boiling phosphorus trichloride with ethylene glycol according to the literature ${ }^{10}$; yield $72 \%$, bp $64.5-66.0^{\circ} \mathrm{C}(40 \mathrm{mmHg})$. 2-Alkoxy-1, 3, 2-dioxaphospholanes ( $\mathrm{R}=\mathrm{Me}, t$ - $\mathrm{Bu}$, neopentyl) were synthesized by the reaction of 2-chloro-1, 3, 2-dioxaphospholane with the corresponding alcohol in the presence of pyridine or triethylamine in benzene, diethyl ether, or ligroin by a method similar to that in the literature. ${ }^{2,11} 2$ Methoxy-1, 3, 2-dioxaphospholane: bp 48.5$49.0^{\circ} \mathrm{C}(20 \mathrm{mmHg})$; yield $40 \%$. Anal. Calcd for $\mathrm{C}_{3} \mathrm{H}_{7} \mathrm{O}_{3} \mathrm{P}: \mathrm{C}, 29.50 \% ; \mathrm{H}, 5.78 \%$; $\mathrm{P}, 25.38 \%$. Found: $\mathrm{C}, 29.52 \%$; $\mathrm{H}, 5.80 \%$; P, 25.36\%. NMR $\left(\mathrm{CDCl}_{3}\right) \delta 3.38\left(\mathrm{~d}, 3, J=10.0 \mathrm{~Hz}, \mathrm{C}_{3} \mathrm{O}\right)$ and $3.6-$ $4.2 \mathrm{ppm}\left(\mathrm{m}, 4, \mathrm{OCH}_{2} \mathrm{CH}_{2} \mathrm{O}\right.$ ); IR 1260, 1180, 1040, 1010 , and $925 \mathrm{~cm}^{-1}$. 2-t-Butoxy-1, 3, 2-dioxaphospholane: bp $74^{\circ} \mathrm{C}(17 \mathrm{mmHg})$; yield $53 \%$. Anal. Calcd for $\mathrm{C}_{6} \mathrm{H}_{13} \mathrm{O}_{3} \mathrm{P}: \mathrm{C}, 43.88 \% ; \mathrm{H}, 7.99 \%$; $\mathrm{P}, 18.88 \%$. Found: C, $43.91 \%$; H, $8.03 \%$; P, $18.79 \%$. NMR $\left(\mathrm{CDCl}_{3}\right) \delta 1.23\left(\mathrm{~s}, 9, \mathrm{C}\left(\mathrm{CH}_{3}\right)_{3}\right)$ and $3.7-4.5 \mathrm{ppm}\left(\mathrm{m}, 4, \mathrm{OCH}_{2} \mathrm{CH}_{2} \mathrm{O}\right)$. 2-Neopentoxy-1, 3, 2-dioxaphospholane: bp $60^{\circ} \mathrm{C} \quad(5$ $\mathrm{mmHg}$ ); yield $64 \%$. Anal. Calcd for $\mathrm{C}_{7} \mathrm{H}_{15} \mathrm{O}_{3} \mathrm{P}$ : C, $47.17 \% ; \mathrm{H}, 8.49 \%$; P, $17.39 \%$. Found: C, $47.21 \% ; \mathrm{H}, 8.59 \%, \mathrm{P}, 17.27 \%$. NMR $\left(\mathrm{CDCl}_{3}\right)$ $\delta 0.88\left(\mathrm{~s}, 9, \mathrm{C}\left(\mathrm{CH}_{3}\right)_{3}\right), 3.43\left(\mathrm{~d}, 2, J=9.0 \mathrm{~Hz}, \mathrm{CH}_{2}\right)$, and 3.7-4.3 ppm (m, 4, OC $\left.\underline{\mathrm{H}}_{2} \mathrm{CH}_{2} \mathrm{O}\right)$. Methylphosphonyl dichloride $\left(\mathrm{CH}_{3} \mathrm{PCl}_{2}\right)$ was synthesized O

from methyl bromide by a modification of the reported method. ${ }^{12-14}$ The synthesis from methyl bromide was easy to control and gave a higher yield than that from methyl chloride or methyl iodide. 2-Methyl-2-oxo-1, 3, 2-dioxaphospholane was synthesized by the reaction of methylphosphonic anhydride ${ }^{15}$ and ethylene oxide.

\section{Procedure}

All the reactions were carried out under nitrogen atmosphere. Polymerization of 2-methoxy-1, 3, 2-dioxaphospholane was carried out in a degassed ampoule containing a measured amount of monomer and methyl iodide as an initiator. The polymerization temperatures were $80,120,150$, and $180^{\circ} \mathrm{C}$. The whole reaction system became viscous and was soluble in methanol. The reaction system was evacuated at $50^{\circ} \mathrm{C}$ under high vacuum $\left(10^{-5}\right.$ $\mathrm{mmHg}$ ) in order to remove as much of the unreacted monomer as possible. The reactions of an alkyl iodide with 2-alkoxy-1, 3, 2-dioxaphospholanes were carried out in a flask under nitrogen atmosphere. For the determination of the reaction rate, the reaction was carried out in an NMR tube in 1,1,2, 2-tetrachloroethane at 40, 70, and $100^{\circ} \mathrm{C}$. The reaction system (NMR tube) was immersed in a thermostatted bath for given intervals. The reaction was stopped by rapid cooling of the reaction system in a dry ice-acetone bath. 
The NMR spectra of the reaction system were recorded at room temperature. The reaction of an alkyl iodide with a 2-alkoxy-1, 3, 2-dioxaphospholane at room temperature was relatively slow compared to the reactions at 40,70 , and $100^{\circ} \mathrm{C}$. Consequently, the time for measuring the spectra was neglected in analyzing the reaction rate. The concentrations of monomer and products were calculated from the peak area ratios between $\mathrm{P}-$ $\mathrm{OCH}_{3}$ or $\mathrm{PO}-\mathrm{CH}_{2}-\mathrm{C}\left(\mathrm{CH}_{3}\right)_{3}$ in monomer and $\mathrm{P}-$ $\mathrm{CH}_{3}$ in the products, using 1,1, 2, 2-tetrachloroethane as an internal standard.

The NMR spectra were recorded on a JEOL model JNM-PMX 60 spectrometer. The gas chromatograph used was a Hitachi model $\mathrm{K} 23$ connected with $1 \mathrm{~m}$ of Silicone GE-SE-30 column. The liquid chromatograph used was a Toyo Soda model HLC 802 UR connected with 4-feet long columns of styrogel, TSK GEL G2000 H8 (exclusion limit $2.5 \times 10^{2} \AA$, TP/F 8000). The columns were eluted with chloroform $(1 \mathrm{~m} / / \mathrm{min})$.

\section{Identification of Reaction Products}

The reaction products were identified mainly spectroscopically. The reaction products of 2methoxy-1, 3, 2-dioxaphospholane with methyl iodide were identified by the retention times in the chromatogram and by NMR analysis. When 2methoxy-1, 3, 2-dioxaphospholane (1.6 g, $1.3 \times$ $\left.10^{-2} \mathrm{~mol}\right)$ was reacted with methyl iodide $(3.7 \mathrm{~g}$, $\left.2.6 \times 10^{-2} \mathrm{~mol}\right)$ in dichloromethane $(1.8 \mathrm{ml})$ under reflux, two reaction products were detected in the gas chromatogram. One product had the same retention time in the gas chromatogram and the same elution volume in liquid chromatogram as authentic 2-methyl-2-oxo-1, 3, 2-dioxaphospholane. Although the two products could not be easily separated, they could be distilled. The NMR spectra of the mixture of the two products, after simple distillation $\left(85-87^{\circ} \mathrm{C} / 0.5 \mathrm{~mm}\right)$, and that of authentic 2-methyl-2-oxo-1, 3, 2-dioxaphospholane have been shown in Figure 1. The signals at $\delta\left(\mathrm{CDCl}_{3}\right) 1.67(\mathrm{~d}, J=17.5 \mathrm{~Hz})$ and $4.0-$ $4.7(\mathrm{~m})$ ppm could be assigned to methyl protons and ring protons of 2-methyl-2-oxo-1, 3, 2dioxaphospholane. Thus, one of the two products was identified as 2-methyl-2-oxo-1, 3, 2dioxaphospholane. When the signals of 2methyl-2-oxo-1, 3, 2-dioxaphospholane were subtracted from the spectrum (b) in Figure 1, the re-

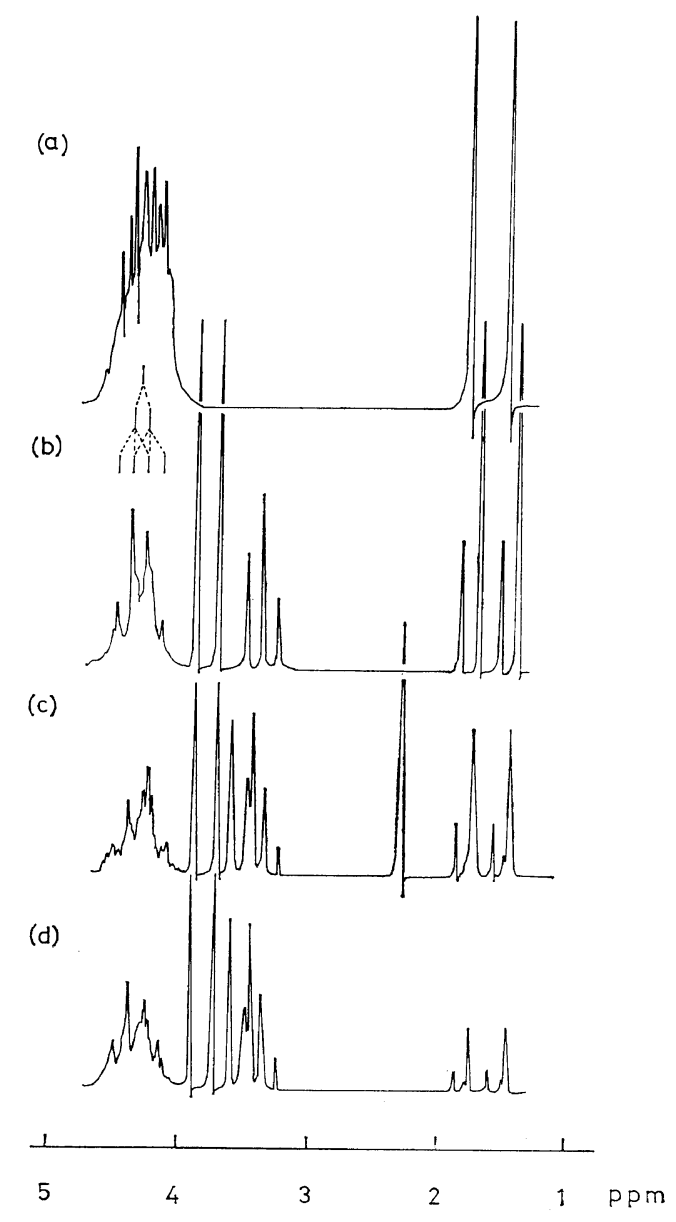

Figure 1. NMR spectra of 2-methyl-2-oxo-1, 3, 2dioxaphospholane and the reaction products from methyl iodide and 2-methoxy-1, 3, 2-dioxaphospholane: (a) 2-methyl-2-oxo-1, 3, 2-dioxaphospholane; (b) the reaction products after distillation; (c) the reaction products; (d) the reaction products from methyl iodide- $d_{3}$; [methyl iodide $]_{0}=3.6 \mathrm{M}$; [2-methoxy-1, 3, 2-dioxaphospholane $=1.8 \mathrm{M} ; \quad\left[\text { methyl iodide- } d_{3}\right]_{0}=$ $0.67 M$.

maining signals were at $\delta\left(\mathrm{CDCl}_{3}\right) 1.45(\mathrm{~d}, 3, J=$ $18.0 \mathrm{~Hz}), 3.38$ (t, 2, $J=7.0 \mathrm{~Hz}), 3.88$ (d, 3, $J=$ $11.0 \mathrm{~Hz})$, and $4.32 \mathrm{ppm}(\mathrm{q}, 2, J=7.0 \mathrm{~Hz})$. These signals could be best understood by considering the structure of the ring-opening product of 2 methoxy-1, 3, 2-dioxaphospholane by methyl iodide, namely, methyl $\beta$-iodoethyl methylphosphonate. The reaction products with methyl iodide- $d_{3}$ were identified by the comparison of the NMR spectrum (Figure 1(d)) with that of the pro- 


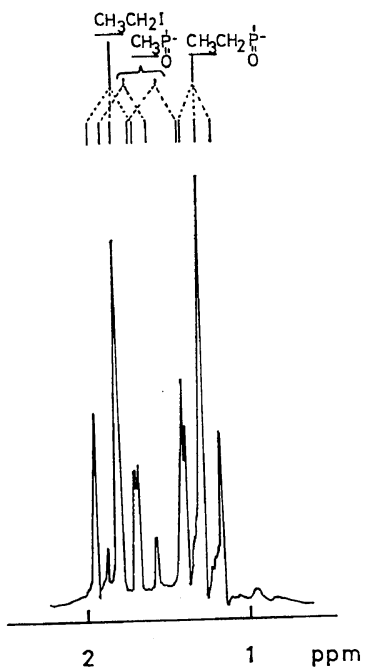

Figure 2. NMR spectrum of the reaction products from ethyl iodide and 2-methoxy-1, 3, 2-dioxaphospholane in $\mathrm{P}-\mathrm{CH}_{3}$ region: [ethyl iodide] $=2.51 \mathrm{M}$; [2-methoxy-1, 3, 2-dioxaphospholane $]_{0}=2.91 \mathrm{M}$.

ducts from methyl iodide. The reaction products with ethyl iodide were identified by NMR analysis (Figure 2). The reaction products of 2-t-butoxy1, 3, 2-dioxaphospholane with methyl iodide were isolated by fractional distillation and identified to be isobutylene and 2-hydro-2-oxo-1, 3, 2dioxaphospholane: bp $80-83^{\circ} \mathrm{C} \quad(0.5 \mathrm{~mm})$; NMR $\left(\mathrm{CDCl}_{3}\right) \delta 7.05\left(\mathrm{~d}, 1, J_{\mathrm{PH}}=722 \mathrm{~Hz}\right)$ and 4.0-4.6 ppm (m, 4); IR $2460(\mathrm{P}-\mathrm{H})$ and 1200 $\mathrm{cm}^{-1}(\mathrm{P}=\mathrm{O})$. The reaction product from 2neopentoxy-1, 3, 2-dioxaphospholane and methyl iodide was isolated by fractional distillation; bp $96-97^{\circ} \mathrm{C}(0.25 \mathrm{~mm})$. This product was identified as neopentyl $\beta$-iodoethyl methylphosphonate by NMR analysis. NMR $\left(\mathrm{CDCl}_{3}\right) \delta 0.95$ (s, 9, C$\left.\left(\mathrm{CH}_{3}\right)_{3}\right), 1.49\left(\mathrm{~d}, 3, J=18.0 \mathrm{~Hz}, \mathrm{P}-\mathrm{CH}_{3}\right), 3.36(\mathrm{t}$, 2, $\left.J=7.0 \mathrm{~Hz}, \mathrm{CH}_{2} \mathrm{I}\right), 3.37\left(\mathrm{~d}, 2, J=5.5 \mathrm{~Hz}, \mathrm{P}-\mathrm{CH}_{2}\right)$, and 4.33 (q (two overlapped triplets), 2, $J_{\mathrm{POCH}}=$ $\left.7.0 \mathrm{~Hz}, J_{\mathrm{CH}_{2} \mathrm{CH}_{2} \mathrm{I}}=7.0 \mathrm{~Hz}, \mathrm{OCH}_{2} \mathrm{CH}_{2} \mathrm{I}\right)$.

\section{RESULTS AND DISCUSSION}

\section{Polymerization of 2-Methoxy-1, 3, 2-dioxaphospho- lane}

2-Methoxy-1, 3, 2-dioxaphospholane can be polymerized by various cationic initiators to high conversion. The formed product was usually a

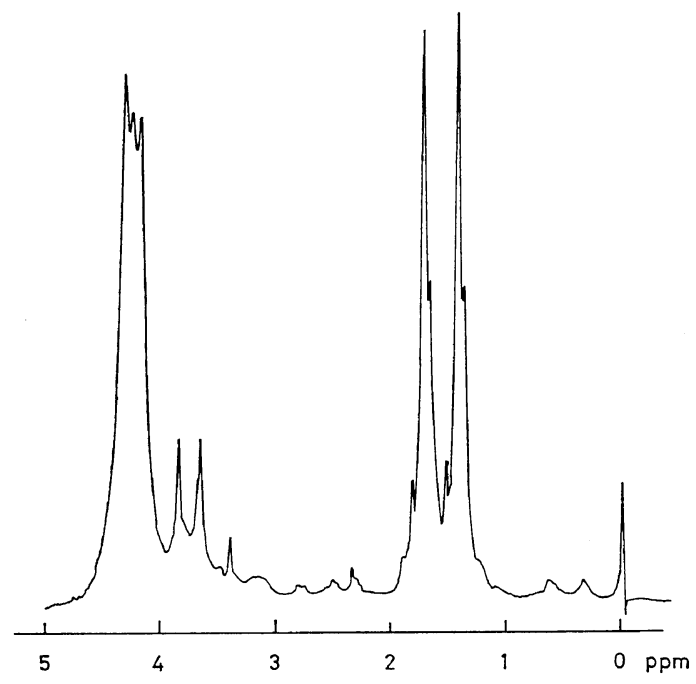

Figure 3. NMR spectrum of the low-molecularweight oligomer induced by methyl iodide at $120^{\circ} \mathrm{C}$ : $M_{w} 500$ (VPO).

low-molecular-weight yellowish jelly-like mass. The solid polymer, if any, was hardly soluble in ordinary organic solvents. The NMR spectrum of the low-molecular-weight, chloroform-soluble oligomer from the polymerization by methyl iodide has been given in Figure 3. The expected structure is poly(2-hydroxyethanephosphonate). The peak area of the methyl group linked to the phosphorus atom, which would have come from the initiator residue, is larger than that of methoxy group linked to the phosphorus atom which would be in the repeating unit. Also, the peak area of the $\mathrm{PCH}_{2}$ group was smaller than that of the $\mathrm{POCH}_{2}$ group. The results of IR analysis also suggested the existence of many $\mathrm{POCH}_{2}$ groups. Thus, the structure of the polymer was not the expected simple poly (2-hydroxyethanephosphonate) but included some units like 1, 2-ethanediphosphonate. Harwood ${ }^{7}$ suggested the formation of 1,2ethanediphosphonate unit by the reinitiation mechanism shown below:

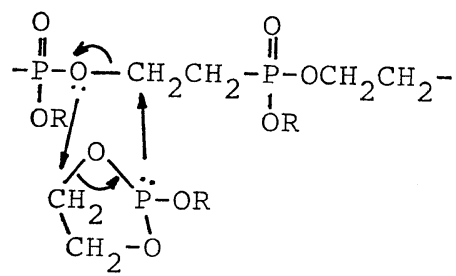


<smiles>[Z]CCOP([R2])(=O)CCP([R2])(=O)OCCOP([R])(=O)CC</smiles>

Table I. Oligomerization of 2-methoxy-1, 3, 2dioxaphospholane by methyl iodide ${ }^{a}$

\begin{tabular}{lcccc}
$\begin{array}{c}\text { Temp, } \\
{ }^{\circ} \mathrm{C}\end{array}$ & $\begin{array}{r}\mathrm{CH}_{3} \mathrm{I}, \\
\mathrm{mol}^{\circ}\end{array}$ & $\begin{array}{c}\text { Time, } \\
\mathrm{h}\end{array}$ & $\begin{array}{c}\text { Yield, } \\
\%\end{array}$ & Appearance \\
\hline 180 & 4.0 & 43 & 100 & Viscous oil \\
150 & 4.0 & 23.5 & 52.5 & Viscous oil \\
120 & 0.5 & 1400 & 100 & Viscous oil \\
80 & 1.0 & 957 & 52 & Viscous oil \\
\hline a & Monomer $(2 \mathrm{ml})$ was polymerized in an ampoule \\
without solvent. & & & \\
b After evacuation under high vacuum $\left(10^{-5} \mathrm{mmHg}\right)$ \\
at $50^{\circ} \mathrm{C}$ for $24 \mathrm{~h}$.
\end{tabular}

$\operatorname{Vogt}^{9}$ suggested an alternating sequence of 1,2ethanediphosphonate units and 2-hydroxyethanephosphonate units. Since, as stated above, in the case of 2-methoxy-1, 3, 2-dioxaphospholane, the $\mathrm{POCH}_{2}$ group is included much more than the $\mathrm{PCH}_{2}$ group in the polymer structure, random reinitiation like Harwood's might have frequently happened.

Elementary Reaction of Methyl Iodide with 2Alkoxy-,1 3, 2-dioxaphospholane

Since it has been shown that the structure of the oligomerization product of 2-methoxy-1, 3, 2dioxaphospholane by methyl iodide was not a simple phosphonate, the elementary reactions of 2-methoxy-1, 3, 2-dioxaphospholane with methyl iodide were studied in order to obtain some information on the reaction mechanism and oligomer structure. The NMR spectrum of the reaction products has been shown in Figure 1(c). The main products were 2-methyl-2-oxo-1, 3, 2-dioxaphospholane and methyl $\beta$-iodoethyl methylphosphonate. The small doublet at $\delta 1.50 \mathrm{ppm}$ disappeared in the distillate and remained in the distillation residue. This indicated that the doublet should be assigned to a methylphosphonyl group in a higher-molecular-weight product. Thus, the elementary reactions between 2-methoxy-1, 3, 2-dioxaphospholane and methyl iodide were the addition of methyl iodide across the phospholane ring via the Arbuzov reaction involving the ring $\mathrm{P}-\mathrm{OCH}_{2}$ bond and the isomerization of the phosphite to phosphonate via the Arbuzov reaction involving the external methoxy-P bond.

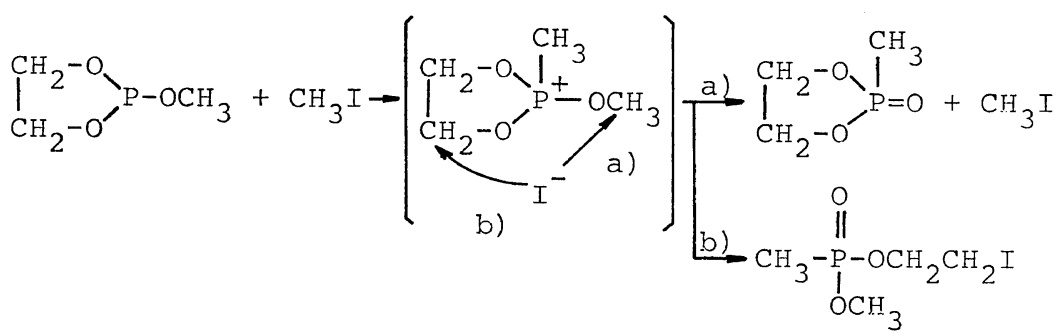

Since the isomerized product, 2-methyl-2-oxo1, 3, 2-dioxaphospholane could not be polymerized under the reaction conditions, the reaction path a) could be a chain-transfer reaction by regeneration of methyl iodide in the growing step.

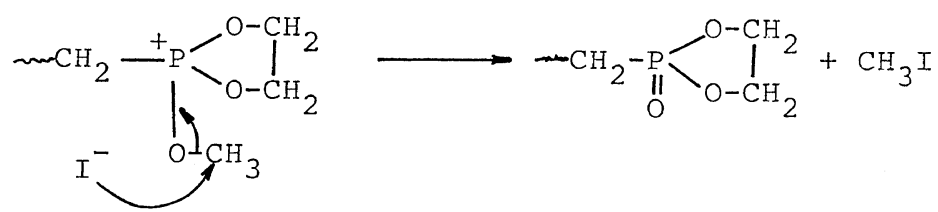

In order to confirm the reaction path a), the reaction of methyl iodide- $d_{3}$ with 2-methoxy-1, 3, 2- dioxaphospholane was carried out. The NMR spectrum of the products has been shown in Figure 
1(d). In the figure, two kinds of $\mathrm{P}-\mathrm{CH}_{3}$ protons are seen, one of which was assigned to that of methyl $\beta$-iodoethyl methylphosphonate and the other was assigned to that of 2-methyl-2-oxo-1, 3, 2-dioxaphospholane. These two compounds would have come from the reaction of 2-methoxy-1, 3, 2-dioxaphospholane with the methyl iodide which was regenerated through reaction path (3)a).
The area ratio of the $\mathrm{P}-\mathrm{CH}_{3}$ protons of 2methyl-2-oxo-1, 3, 2-dioxaphospholane and of methyl $\beta$-iodoethyl methylphosphonate was constant, $1: 2.7$, at $70^{\circ} \mathrm{C}$. This value was the same in the reaction between methyl iodide and 2methoxy-1, 3, 2-dioxaphospholane. The ratio between the ring-opening and the isomerization reactions changes according to the reaction conditions. It is generally considered that the ring-opening product is formed first, then the ring formation leading to the isomerized product proceeds. $^{16}$ However, only an isomerized product was formed and no ring-opening product could be detected in some cases. ${ }^{17,18}$ It is recognized that the ratio is affected very much by the reaction temperature and the substituents in the dioxaphospholane ring. Under the reaction conditions employed, the ratio between ring-opening and isomerization products did not change with reaction time, which might indicate that the two elementary reactions proceed in a one-step reaction via the same phosphonium intermediate.

\section{Reaction of 2-Methoxy-1, 3,-Dioxaphospholane} with Ethyl Iodide

In order to form a high polymer, the reaction path (1)-b) must be repeated. Ethyl iodide could be considered as a model compound for the propagating end. Conceivably, it is possible to evaluate roughly the possibility of repeating the reaction path (1)-b). The time-conversion relationships have been given in Figure 4. Although the reaction was very slow, 2-methoxy-1, 3, 2dioxaphospholane was consumed faster than ethyl iodide. This could be understood as a result of the faster reaction of methyl iodide, regenerated via reaction (4)-a), with 2-methoxy-1, 3, 2-dioxaphospholane according to reaction (1).

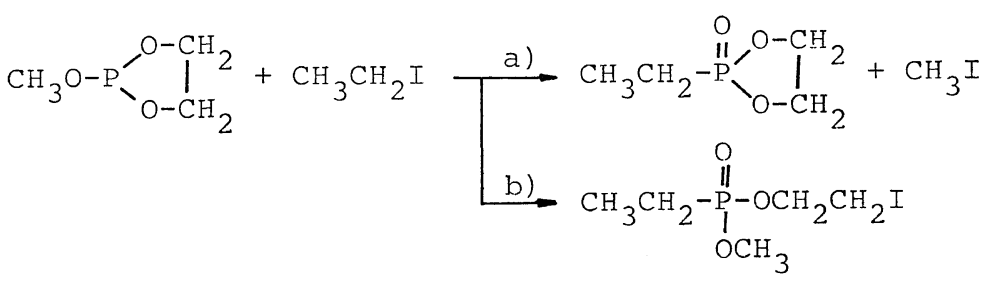

The NMR spectrum of the reaction products of the region of $\mathrm{P}$-alkyl protons has been shown in Figure 2. It shows that two kinds of $\mathbf{P}-\mathrm{CH}_{3}$ signals have appeared with the consumption of ethyl iodide. The sum of the moles of $\mathrm{P}-\mathrm{CH}_{2} \mathrm{CH}_{3}$ and of the two kinds of $\mathrm{P}-\mathrm{CH}_{3}$ just corresponded to those of the consumed monomer. The two kinds of methylphosphonyl signals were reasonably assigned to those in 2-methyl-2-oxo-1, 3, 2-dioxaphospholane and methyl $\beta$-iodoethyl methylphosphonate. Thus, the elementary reaction between ethyl iodide and 2-methoxy-1, 3, 2-dioxaphospholane would 


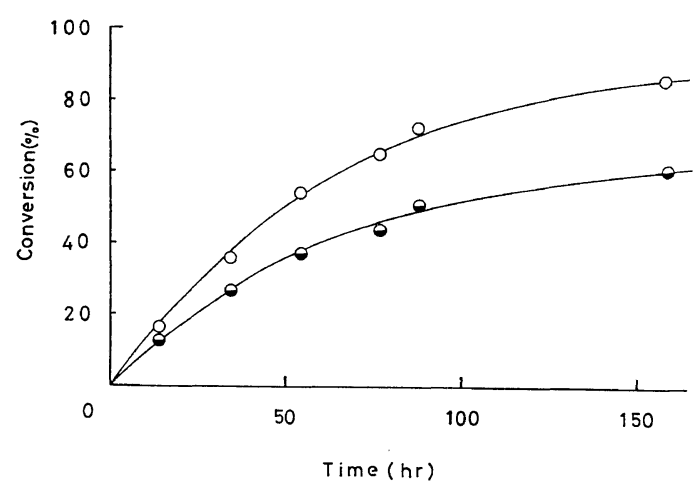

Figure 4. Time-conversion relationship in the course of the reaction of ethyl iodide with 2-methoxy-1, 3, 2-dioxaphospholane at $70^{\circ} \mathrm{C}$ : $\odot$, ethyl iodide; $\bigcirc, 2-$ methoxy-1, 3, 2-dioxaphospholane; [ethyl iodide]= $2.51 \mathrm{M}$; [2-methoxy-1, 3, 2-dioxaphospholane] $=2.91$ $M$.

be written as eq 4 . The regenerated methyl iodide would react further with monomer at a much faster rate than ethyl iodide. Since the consumption of ethyl iodide was slow and no free methyl iodide was detected under the conditions where 2-methyl2-oxo-1, 3, 2-dioxaphospholane and methyl $\beta$ iodoethyl methylphosphonate formed, the reaction of ethyl iodide with 2-methoxy-1, 3, 2-dioxaphospholane was much slower compared to that of methyl iodide. Moreover, the reaction paths (4)-a) and b) were not selective. From these facts, it was supposed that the propagation reaction was quite slow, with a high percentage of chain transfers. This could be the reason why a high polymer could not be obtained from 2-methoxy-1, 3, 2-dioxaphospholane by cationic polymerization with methyl iodide.

\section{Reaction of 2-tert-Butoxy-1, 3, 2-dioxaphospholane with Methyl Iodide}

Since it has been clearly found that the Arbuzov reaction was sensitive to steric hindrance, the reaction of 2-t-butoxy-1, 3, 2-dioxaphospholane with methyl iodide was studied. However, quantitative evolution of isobutylene and formation of 2 hydro-2-oxo-1, 3, 2-dioxaphospholane were observed even at $0^{\circ} \mathrm{C}$ with a catalytic amount of methyl iodide.

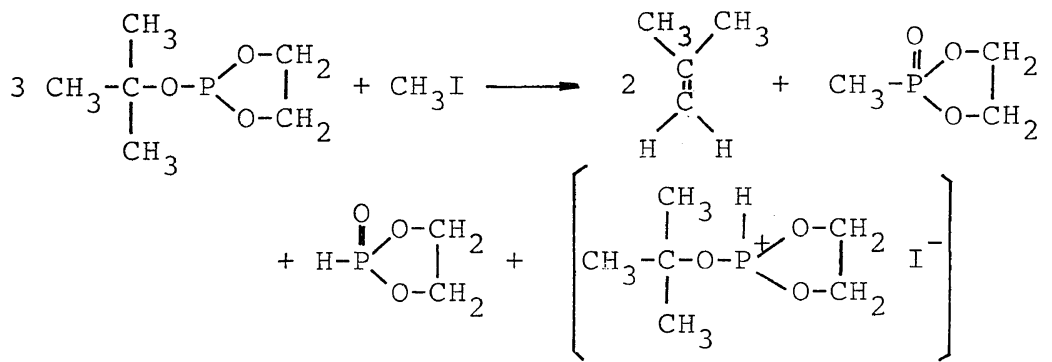

Reaction of 2-Neopentoxy-1, 3, 2-Dioxaphospholane with Methyl Iodide

In order to avoid the $\beta$-elimination reaction of the intermediate phosphonium salt, 2-neopentoxy-1, 3, 2-dioxaphospholane was synthesized as a monomer bearing a bulky external alkoxy group to reduce the isomerization reaction, and its reaction with methyl iodide was studied at $95^{\circ} \mathrm{C}$. The only product in this case was the ring-opening product.

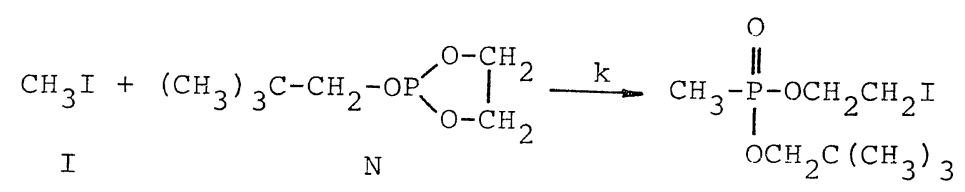

The reaction rate was analyzed according to a second-order law. The value of $k$ was determined to be $(2 \pm 0.1) \times 10^{-4} l \mathrm{~mol}^{-1} \mathrm{~s}^{-1}$ at $95^{\circ} \mathrm{C}$. Since it was shown that the only elementary reaction between 2-neopentoxy-1, 3, 2-dioxaphospholane

and methyl iodide was a ring-opening reaction, this monomer could potentially be polymerized by methyl iodide. However, after $301 \mathrm{~h}$ of reaction with $3.2 \mathrm{~mol} \%$ of methyl iodide at $100^{\circ} \mathrm{C}$, only a jelly-like product was obtained. 


\section{Y. KaWAKami, K. MiYata, and Y. Yamashita}

Reaction Rate of Methyl Iodide with 2-Alkoxy-1,

\section{3, 2-dioxaphospholane}

The reaction scheme of methyl iodide and 2methoxy-1, 3, 2-dioxaphospholane was described in eq 1 . The reaction rate was analyzed as a secondorder reaction.

$$
\begin{aligned}
-\frac{\mathrm{d} M}{\mathrm{~d} t} & =\left(k_{\mathrm{a}}+k_{\mathrm{b}}\right) M I \\
\frac{\mathrm{d} A}{\mathrm{~d} t} & =k_{\mathrm{a}} M I \\
\frac{\mathrm{d} B}{d t} & =k_{\mathrm{b}} M I
\end{aligned}
$$

Here, $k_{\mathrm{a}}$ and $k_{\mathrm{b}}$ are the second-order rate constants for the reaction paths (1)-a) and (1)-b), and $M, I$, $A$, and $B$ stand for concentrations of 2-methoxy-1, 3, 2-dioxaphospholane, methyl iodide, 2-methyl-2oxo-1, 3, 2-dioxaphospholane, and methyl $\beta$ iodoethyl methylphosphonate, respectively. The ratio of $\mathrm{CH}_{3}-\mathrm{P}$ in $A$ and $B$, determined by NMR analysis, was constant at any given time. Consequently $B / A$ could be taken to be constant.

$$
\begin{aligned}
B / A & =K \\
M_{0}-M & =A+B \\
I & =I_{0}-B
\end{aligned}
$$

Here, $M_{0}$ and $I_{0}$ stand for the initial concentrations of monomer and methyl iodide, respectively. Substituting of eq. 10, 11, and 12 into eq 8 one can get,

$$
\frac{\mathrm{d} A}{\mathrm{~d} t}=k_{\mathrm{a}}\left[M_{0}-(1+K) A\right]\left[I_{0}-K A\right]
$$

Considering $A=0$ at $t=0$, the integrated form is

$$
\ln \frac{I_{0}-K A}{M_{0}-(1+K) A}=\left[(K+1) I_{0}-K M_{0}\right] k_{\mathrm{a}} t+\ln \frac{I_{0}}{M_{0}}
$$

The constant value $K$ was determined by NMR analysis as 3.1 at $40^{\circ}, 2.7$ at $70^{\circ}$, and 2.8 at $100^{\circ} \mathrm{C}$, respectively. At $40^{\circ} \mathrm{C}, 70^{\circ} \mathrm{C}$, and $100^{\circ} \mathrm{C}$, eq 13 can be simplified to eq 14,15 , and 16 , respectively.

$$
\begin{aligned}
& \ln \frac{I_{0}-3.2 A}{M_{0}-4.1 A}=\left(4.1 I_{0}-3.1 M_{0}\right) k_{\mathrm{a}} t+\ln \frac{I_{0}}{M_{0}} \\
& \ln \frac{I_{0}-2.7 A}{M_{0}-3.7 A}=\left(3.7 I_{0}-2.7 M_{0}\right) k_{\mathrm{a}} t+\ln \frac{I_{0}}{M_{0}} \\
& \ln \frac{I_{0}-2.8 A}{M_{0}-3.8 A}=\left(3.8 I_{0}-2.8 M_{0}\right) k_{\mathrm{a}} t+\ln \frac{I_{0}}{M_{0}}
\end{aligned}
$$

Table II. Change in the concentration of $A$ in the course of reaction of 2-methoxy-1, 3, 2dioxaphospholane with methyl iodide at $40^{\circ} \mathrm{C}^{\mathrm{a}}$

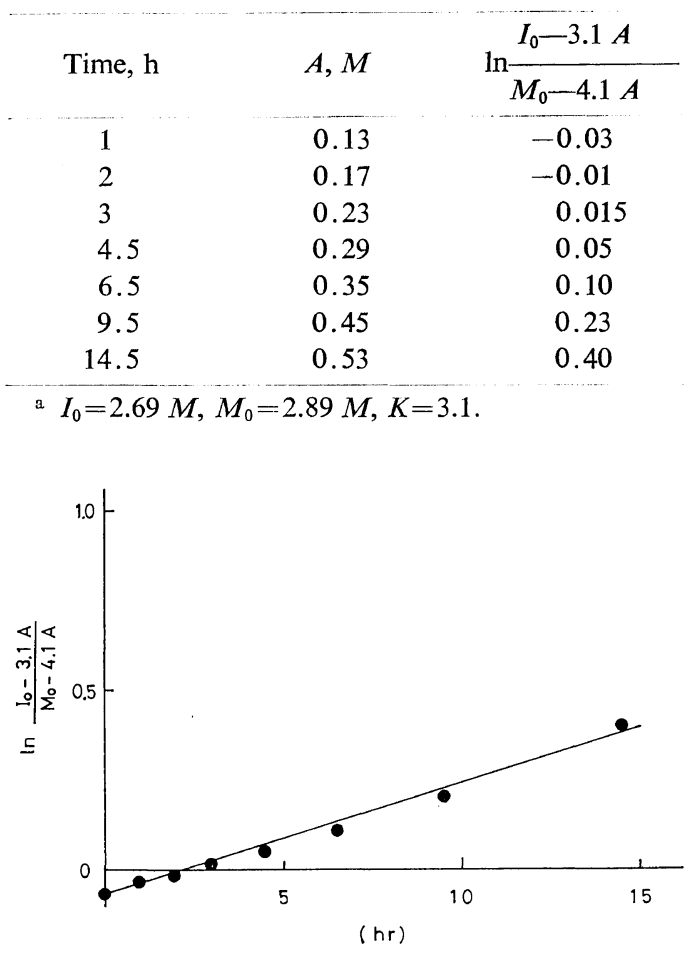

Figure 5. Second-order plot of the reaction between methyl iodide and 2-methoxy-1, 3, 2-dioxaphospholane at $40^{\circ} \mathrm{C}$ : [methyl iodide] $=2.69 \mathrm{M}$; [2-methoxy-1, 3, 2-dioxaphospholane] $=2.89 M ; K=3.1$.

A typical example of concentrations of $A$ evaluated by NMR at a given time has been tabulated in Table II. The plot of eq 14 has been given as Figure 5. From the slopes of the plots the rate constant $k_{\mathrm{a}}$ can be calculated to be $(3.8 \pm 0.2) \times 10^{-5}$ $l \mathrm{~mol}^{-1} \mathrm{~s}^{-1}$ at $40^{\circ} \mathrm{C}, \quad(8.9 \pm 0.2) \times 10^{-5} l \mathrm{~mol}^{-1}$ $\mathrm{s}^{-1}$ at $70^{\circ} \mathrm{C}$, and $(8.0 \pm 0.3) \times 10^{-4} l \mathrm{~mol}^{-1} \mathrm{~s}^{-1}$ at $100^{\circ} \mathrm{C}$ and $k_{\mathrm{b}}$ can be calculated from the values of $k_{\mathrm{a}}$ to be $1.2 \times 10^{-5} \mathrm{lmol}^{-1} \mathrm{~s}^{-1}$ at $40^{\circ} \mathrm{C}, 2.4 \times 10^{-4} \mathrm{l}$ $\mathrm{mol}^{-1} \mathrm{~s}^{-1}$ at $70^{\circ} \mathrm{C}$, and $2.8 \times 10^{-3} l \mathrm{~mol}^{-1} \mathrm{~s}^{-1}$ at $100^{\circ} \mathrm{C}$. The activation energy for the reaction paths a) and b) were $(20 \pm 2) \mathrm{kcal} / \mathrm{mol}$ and $(19 \pm 2)$ $\mathrm{kcal} / \mathrm{mol}$, respectively. Both values were very similar. The ratio between the two reaction paths might not change so much even under polymerization condition $\left(120^{\circ} \mathrm{C}, 150^{\circ} \mathrm{C}\right)$. Consequently, a rather high percentage of the elementary reaction 
of 2-methoxy-1, 3, 2-dioxaphospholane was an isomerization process even under the polymerization condition. This type of isomerization reaction would be a chain-transfer reaction in the propagation step, as shown in eq 2. This could be the reason why high polymers were not formed in the polymerization of 2-methoxy-1,3,2-dioxaphospholane by methyl iodide, although high conversion of monomer could be attained.

\section{REFERENCES}

1. K. A. Petrov, E. E. Nifantev, and I. I. Sopikova, Vysokomol. Soedin., 2, 685 (1970).

2. K. A. Petrov, E. E. Nifantev, L. V. Khorhoyann, M. I. Merkulova, and V. F. Voblinkov. Vysokomol. Soedin., 4, 246 (1962).

3. T. Mukaiyama, T. Fujisawa, Y. Tamura, and Y. Yokota, J. Org. Chem., 29, 2572 (1964).

4. T. Fujisawa, Y. Yokota, and T. Mukaiyama, Bull. Chem. Soc. Jpn., 40, 147 (1967).

5. T. Shimidzu, T. Hakozaki, T. Kagiya, and K. Fukui, J. Polym. Sci., Part B, 3, 871 (1965).

6. T. Shimidzu, T. Hakozaki, T. Kagiya, and K. Fukui, Bull. Chem. Soc. Jpn., 39, 562 (1966).
7. H. J. Harwood and N. K. Patel, Macromolecules, 1, 233 (1968).

8. Y. Yamashita, J. Polym. Sci., Polym. Symp., 56, 447, (1976).

9. W. Vogt and N. U. Ahmad, Makromol. Chem., 178, 1711 (1977).

10. H. J. Lucas, F. W. Mitchell, and C. N. Scully, J. Am. Chem. Soc., 72, 5491 (1950).

11. A. Y. Arbuzov and V. M. Zaroastrova, Izv. Akad. Nauk, SSSR, Otdel. Khim. Nauk, 770 (1950).

12. J. P. Clay, J. Org. Chem., 16, 892 (1951).

13. A. M. Kinnear and E. A. Perren, J. Chem. Soc., 3437 (1952).

14. V. G. Gruzdev, K. V. Karavanov, S. Z. Ivin, I. S. Mazel, and V. V. Tarasov, Zh. Obsh. Khim., 37, 450 (1967).

15. S. R. Landaner and H. N. Rydon, J. Chem. Soc., 2224 (1953).

16. A. E. Arbuzov and N. A. Razumova, Doklady Akad. Nauk, SSSR, 97, 445 (1954).

17. A. E. Arbuzov and M. M. Azanovskaya, Izv. Akad. Nauk, SSSR, Otdel. Khim. Nauk, 473 (1949).

18. F. W. Mitchell, Jr., and H. J. Lucas, J. Am. Chem. Soc., 72, 5779 (1950). 